\title{
ANALYSIS OF METHODS OF PROVIDING PUBLIC TRANSPORT PRIORITY IN CITIES
}

\author{
ANATOLY PISTSOV \& DMITRII ZAKHAROV \\ Department of Road Transport Operation, Industrial University of Tyumen, Russia
}

\begin{abstract}
In recent years, the Russian Federation cities have been actively implementing the concept of "priority for the development of public transport". The most common measure for the implementation public transport priority in Russian Federation is the organization of dedicated lanes. Most often, lanes for public transport are created by reducing the number of lanes for cars and trucks. This method effectiveness is well studied, and it is also known that this measure leads to deterioration in traffic parameters for private vehicles. The article discusses an alternative variant of the public transport priority on intersections with the use of traffic light adaptive control. The analysis of the advantages and disadvantages of two algorithms for adaptive control of traffic light objects is carried out according to the criterion of reducing the delay time of public transport when driving through intersections. With the help of imitation micromodeling, the dependence the delay time on the traffic intensity at a separate intersection was established for the basic variant, the variant with a lane for public transport, two variants of the active priority and the combined variant "active + passive" priority. For all variants, a comparative assessment was made of the deterioration of the driving parameters for personal cars and the improvement for public transport. The methods of granting the public transport priority were ranked according to the criterion of efficiency (travel time delay) for vehicles and all transport system users (drivers and passengers). It was found that in terms of average user travel time delay, passive priority reduces delay by $11.2 \%$ on average across the board. Using the combined method (active + passive) reduces user travel time delay by $17.1 \%$. Also, using the combined method reduces the negative effect on personal vehicles compared to passive ones.
\end{abstract}

Keywords: public transport, public transport priority, active priority, intelligent transport systems, transport modelling.

\section{INTRODUCTION}

During the COVID-19 coronavirus pandemic, population mobility has changed. In 2020 2021, the total number of movements decreased [1], the number and share of movements by public transport (PT) [2] decreased, and the share of movements by personal transport increased. To prevent infection with coronavirus, medical specialists recommend maintaining a social distance of $1 \mathrm{~m}$ in public places, including in public transport. During rush hours in public transport in large cities, due to the congestion of a large number of people, the social distance is often not observed [3].

According to the authors of [4], the requirement to maintain a social distance of $1-1.5 \mathrm{~m}$ casts doubt on the very concept of public transport (PT). The economic and social impacts of the COVID-19 outbreak on PT go beyond service quality and health risks and impact financial viability, social equity and sustainable mobility. There is a risk that, if the PT sector is perceived to be poorly transitioning to post-pandemic conditions, the perception of PT as unhealthy will spread and possibly continue. The authors talk about the need to research alternative strategies and scenarios for public health, in particular measures to reduce the congestion of people in PT.

For people who live in large cities and do not have private cars, it is important to preserve their health when traveling by public transport. This requires reducing the occupancy of the vehicle (bus, trolleybus, tram, subway car). The number of PT vehicles is limited (limited), therefore other options should be considered. One of these options is to increase the number 
of PT trip by increasing the speed of communication and reducing the time delays when crossing intersections. This can be achieved through the creation of lanes for PT and the introduction of the crossing intersections priority for PT [5]-[7].

Creation of lanes for PT by reducing the number of lanes for individual transport leads to an increase in the delay time for drivers and individual transport passengers [8]. The infrastructure for PT has an impact on the parameters of the urban transport system. The creation of the bus rapid transit (BRT) has an even greater impact on the public transport performance [9]-[11]. The authors of the works [12], [13] studied the factors that affect the proportion of movement on PT, personal transport and bicycles and on foot. Reducing the loss of time when traveling on PT is one of the important factors when choosing a method of transportation.

The introduction of adaptive control of traffic lights [14], [15] and the use of Big Data [16] are one of the most effective measures to reduce the loss of time for movement. To assess the effectiveness of the measures applied for the development of health and safety and transport infrastructure, simulation modelling is used [17]. The simulator used to optimize the schedule, to evaluate passenger load and bus fleet utilization scenarios [18].

\section{MATERIALS AND METHODS}

To assess the change in traffic parameters when the public transport priority (PTP) was implemented, traffic simulation was used in the PTV Vissim 11 program. A model of an regulated X-shaped intersection of two highways with six traffic lanes was created. Public transport routes pass through the intersection on the directions 1 and 3 (Fig. 1). Second road (directions 2 and 4) has not any PT routes. Despite the equal intensity, the direction with the movement of buses in this work is considered the main one, the other direction is secondary.

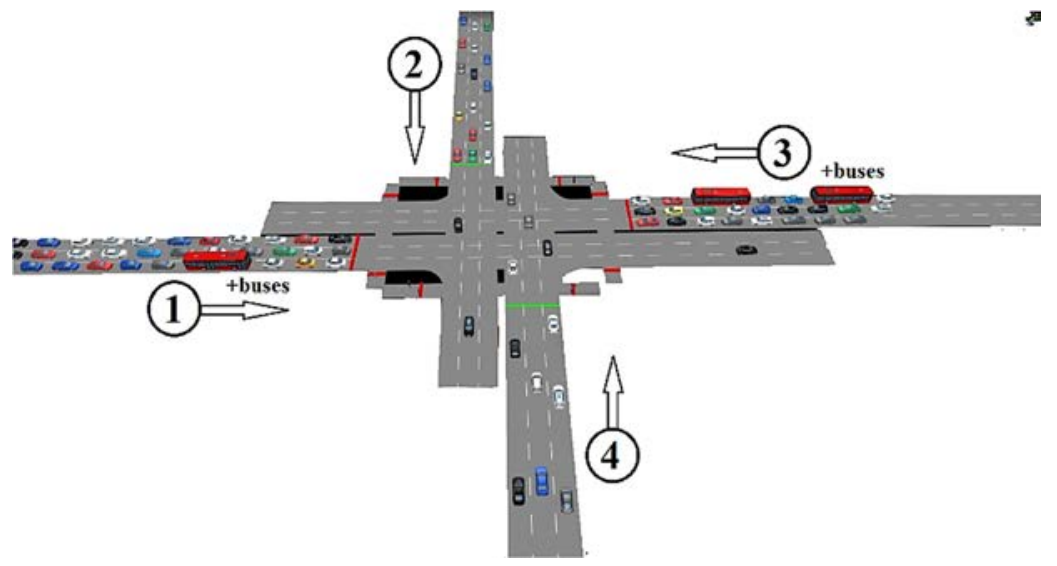

Figure 1: General view of the intersection.

The traffic flow at the intersection are the same in all directions. Thus, the model used the same phase coefficients when the traffic light was operating. When creating a simulation model, the standard settings of the PTV Vissim program were accepted. Three phases of traffic light regulation were used in the model: movement of directions 1 and 3, movement of directions 2 and 4, and a separated pedestrian phase.

The bus traffic is 120 buses per hour and is constant. Personal vehicle traffic is variable and ranges from 1,600 to 2,060 vehicles per hour at each approach to an intersection. 
During the simulation, six micromodels were created:

1. Basic option (no PTP measures).

2. Creation of a bus dedicated lane by reducing lanes for personal transport from three to two (passive PTP). In the Russian Federation, it is customary to convert the right traffic lane into a bus lane and allow private cars drivers to turn right through this lane.

3. "Green extension" (active PTP). When a bus approaches, which does not have time to cross the stop line at a permitting traffic light, the phase is extended [14].

4. "Stage recall" (active PTP). If there are six buses in the queue in total on the priority direction, the phase is switched on early [14].

5. Combination of dedicated public transport lane and "green extension".

6. Combination of dedicated public transport lane and "stage recall".

In the Russian Federation cities, there are systems that allow to track the movement of the bus in real time. When creating a simulation model, standard Vissim transport detectors were used. One detector was located on the approach in front of the intersection, the second detector was located at the intersection itself. The second detector monitored the moment when bus crossing the intersection. These detectors were required solely for simulation.

On real traffic lights and vehicles, they are replaced by the GLONASS/GPS system with continuous tracking of the approach of the bus.

The maximum change in the duration of the phases during active PTP operation was limited at $25 \%$. Traffic light control algorithms were compiled in the VisVap program. To preserve the total cycle time and the operation of the traffic light objects coordination systems, the time was redistributing between the phases. That is, by adding 5 seconds for the main direction, the duration of the phase for the secondary direction was reducing by 5 seconds. The duration of the pedestrian phase was not changing.

For each of the options, measurements were made at different traffic intensities. The following key indicators were used:

1. Vehicles speed in general for the model.

2. Buses speed.

3. Vehicles speed separately for the main and secondary directions.

4. Total vehicles average delay in general for the model.

5. Total buses average delay in general for the model.

6. Total vehicles average delay of separately for the main and secondary directions.

\section{RESULTS AND DISCUSSION}

With the help of modeling, the results presented in Table 1 were obtained. With an increase in traffic intensity in all six variants, the bus delay time in the model increases. The largest increase in the delay time with increasing traffic intensity is observed in the scenario without using PTP. The smallest influence of traffic volume on bus delay time is observed in scenarios using combined priority options (active + passive).

The maximum reduction in the buses delay time relative to the basic variant is observed in the combined method (bus line + "stage recall"). Considering the slope of the trend lines to the abscissa axis, it can be concluded that each PTP method is sensitive to changes in traffic intensity at the intersection.

At low traffic volumes, the delay time varies from 36.6 to 40.8 seconds $(11.3 \%)$ when using different PTP methods (Fig. 2). At high flow, the delay time varies from 40.3 to 78.0 seconds $(93.6 \%)$. 
Table 1: Buses average delay time.

\begin{tabular}{|c|c|c|c|c|c|c|}
\hline \multirow{2}{*}{$\begin{array}{c}\text { Flow, } \\
\text { veh/h }\end{array}$} & \multicolumn{7}{|c|}{$\begin{array}{c}\text { No } \\
\text { priority }\end{array}$} & Bus line & $\begin{array}{c}\text { Green } \\
\text { extension }\end{array}$ & $\begin{array}{c}\text { Stage } \\
\text { recall }\end{array}$ & $\begin{array}{c}\text { Bus line }+ \\
\text { green extension }\end{array}$ & $\begin{array}{c}\text { Bus line }+ \\
\text { stage recall }\end{array}$ \\
\cline { 2 - 7 } & \multicolumn{7}{|c|}{ Delay time, seconds } \\
\hline 2,060 & 78.0 & 44.4 & 70.2 & 43.9 & 40.3 & 40.6 \\
\hline 2,030 & 54.3 & 43.3 & 50.9 & 42.3 & 40.7 & 38.8 \\
\hline 1,990 & 53.8 & 43.9 & 47.6 & 45.7 & 40.8 & 40.1 \\
\hline 1,950 & 49.8 & 43.1 & 44.3 & 44.3 & 39.4 & 38.9 \\
\hline 1,900 & 51.0 & 41.9 & 46.6 & 39.7 & 38.9 & 39.3 \\
\hline 1,800 & 44.6 & 42.0 & 40.3 & 40.0 & 38.0 & 38.6 \\
\hline 1,700 & 43.7 & 39.6 & 40.0 & 39.2 & 36.8 & 38.2 \\
\hline 1,600 & 40.8 & 38.6 & 40.0 & 37.3 & 36.6 & 37.3 \\
\hline
\end{tabular}

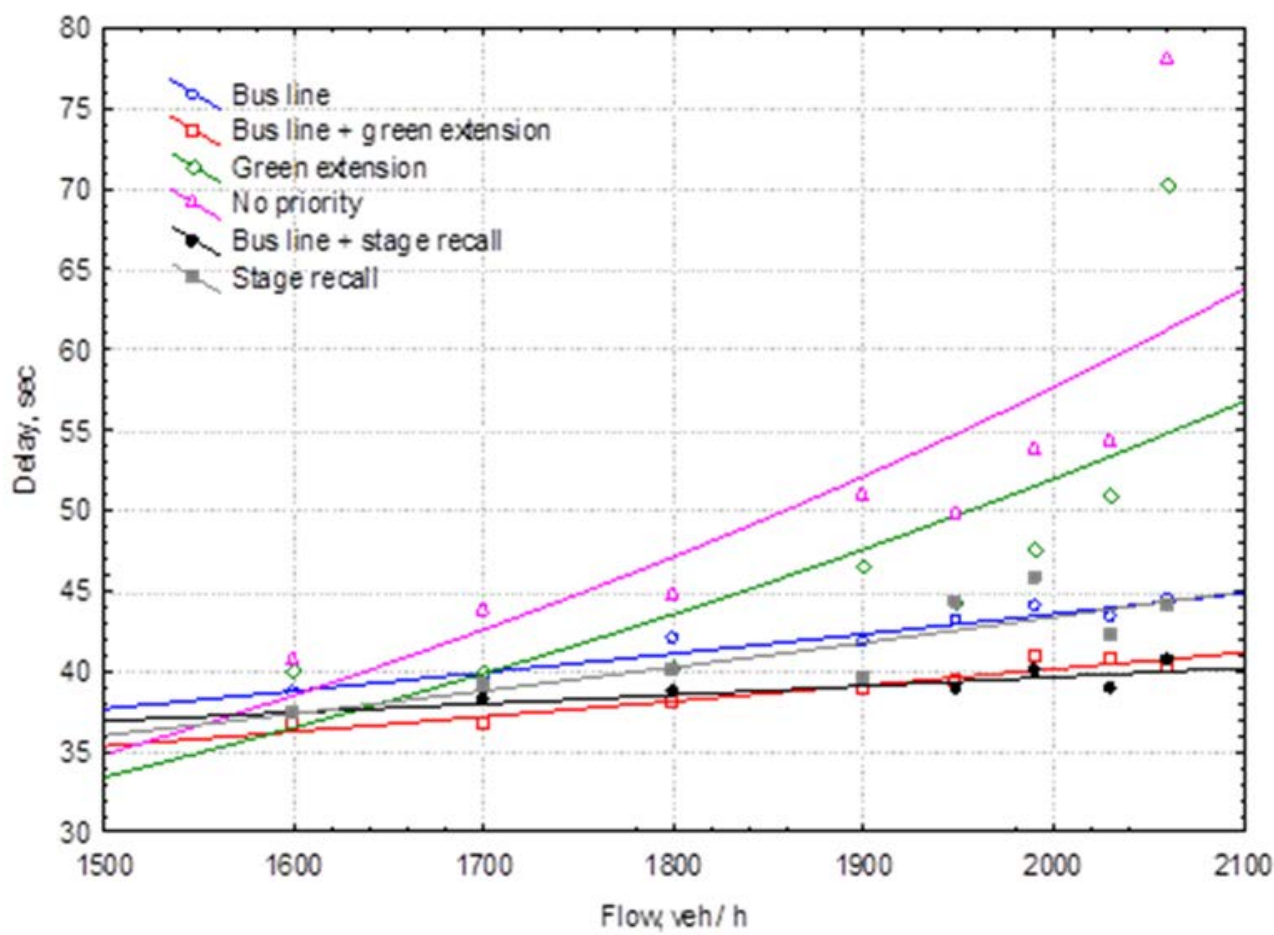

Figure 2: Influence of traffic intensity on bus delays when using different PTP methods.

Combined priority options (active + passive) have the least sensitivity to changes in traffic intensity. The difference between the delay time at high and low traffic intensity is $9 \%$ (bus line + "stage recall") and $11.5 \%$ (bus line + "green extension"). Of the two active priority modes, the "green extension" has a higher sensitivity to traffic intensity. Increase in the delay time with increasing traffic intensity from $40.0(1,600 \mathrm{veh} / \mathrm{h})$ to $70.2(2,060 \mathrm{veh} / \mathrm{h}) \mathrm{seconds}$ $(75.6 \%)$. Similar results were obtained for the vehicles delay time (Table 2). 
Table 2: Cars average delay time.

\begin{tabular}{|c|c|c|c|c|c|c|}
\hline \multirow{2}{*}{$\begin{array}{c}\text { Flow, } \\
\text { veh/h }\end{array}$} & $\begin{array}{c}\text { No } \\
\text { priority }\end{array}$ & Bus line & $\begin{array}{c}\text { Green } \\
\text { extension }\end{array}$ & $\begin{array}{c}\text { Stage } \\
\text { recall }\end{array}$ & $\begin{array}{c}\text { Bus line }+ \\
\text { green extension }\end{array}$ & $\begin{array}{c}\text { Bus line }+ \\
\text { stage recall }\end{array}$ \\
\hline 2,060 & 128.7 & 231.3 & 133.3 & 190.1 & 236.6 & 238.0 \\
\hline 2,030 & 84.7 & 176.7 & 116.7 & 185.9 & 204.2 & 210.9 \\
\hline 1,990 & 79.2 & 145.9 & 101.0 & 179.4 & 140.0 & 155.2 \\
\hline 1,950 & 47.9 & 77.1 & 84.1 & 119.9 & 87.6 & 129.6 \\
\hline 1,900 & 44.5 & 56.3 & 48.5 & 122.5 & 64.1 & 94.9 \\
\hline 1,800 & 38.7 & 47.7 & 41.6 & 41.7 & 46.3 & 45.7 \\
\hline 1,700 & 39.6 & 41.3 & 41.0 & 38.7 & 41.7 & 40.6 \\
\hline 1,600 & 36.8 & 37.9 & 36.9 & 38.5 & 38.2 & 39.2 \\
\hline
\end{tabular}

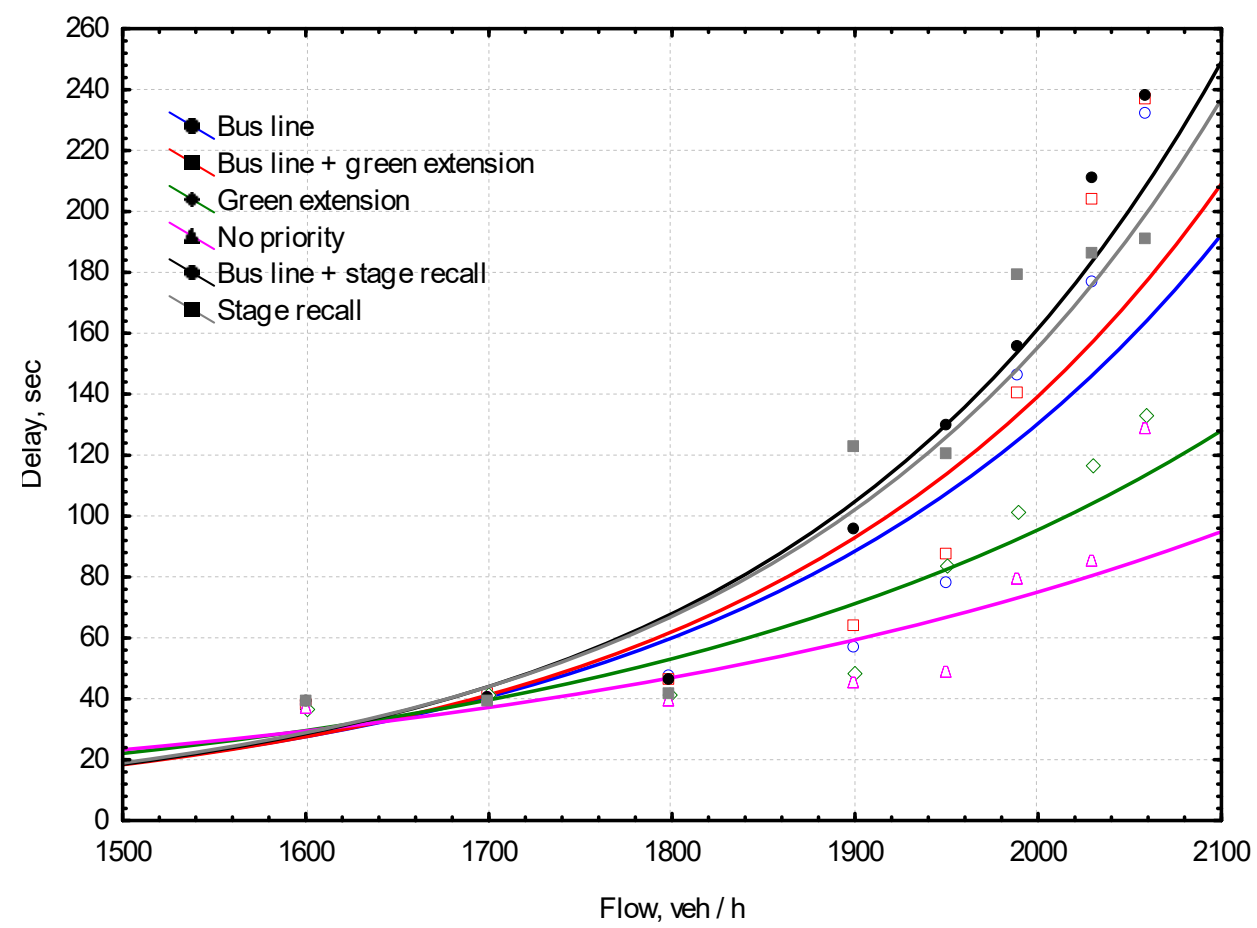

Figure 3: Influence of traffic intensity on car delays when using different PTP methods.

At low traffic volumes, the delay time for personal transport varies from 36.8 to 39.2 seconds (6.4\%) when using different priority methods (Fig. 3). At high traffic flow, the delay time varies from 128.7 to 238.0 seconds $(84.9 \%)$.

Combined priority options (active + passive) are most sensitive to changes in traffic intensity. The difference between the delay time at high and low traffic intensity is $508.0 \%$ (bus line + "stage recall") and 519.2\% (bus line + "green extension"). Of the two active priority modes, the green extension has a lower sensitivity to traffic intensity. Increase in the 
delay time with increasing traffic intensity from $36.9(1,600 \mathrm{veh} / \mathrm{h})$ to $133.3(2,060 \mathrm{veh} / \mathrm{h})$ seconds $(261.4 \%)$. It should be noted that without PTP using, with an increase in traffic intensity, the delay time for cars increases by $249.8 \%$ (from 36.8 to 128.7 seconds).

The least negative impact on the movement of personal transport is observed when using the "green extension". With a traffic intensity of 1,990 vehicles per hour, the delay time for vehicles using this control method increases by $27.6 \%$ compared to the base case. In comparison, the use of a dedicated bus lane results in an $84.3 \%$ increase in vehicle delays at the same traffic flow.

The use of "stage recall" has a more significant effect on the movement of personal vehicles (an increase in delay of $126.7 \%$ with a traffic intensity of 1,990 vehicles/h) compared to a dedicated lane or combined options.

When planning PTP measures, it is important to consider not only vehicle delays, but also the loss of time for all road users.

To estimate the delay time of passengers, coefficients reflecting the number of users in the car and on the bus were used. The average number of transport system users in a private car is 1.5. The average number of passengers on the bus is 30 .

As a result of calculating the delay time for each user of the transport system, all PTP methods were ranked according to the degree of their impact on users (Fig. 4).

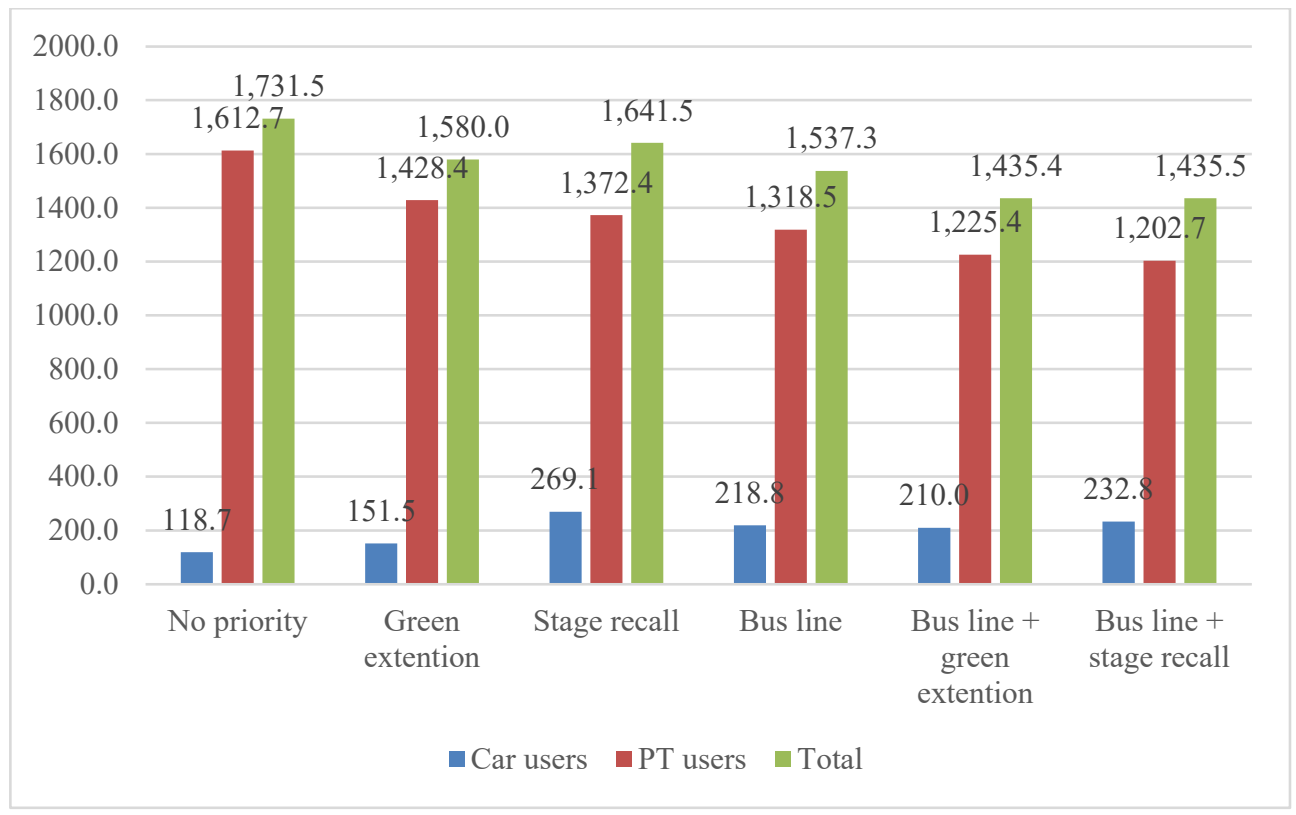

Figure 4: Transport system user delay time with a traffic intensity of $1,990 \mathrm{veh} / \mathrm{h}$ from each direction.

The shortest delay time for users of the transport system is achieved with combined PTP methods (dedicated bus lane + "green extension"/"stage recall"). With this PTP method, the lowest value of the total delay time for the transport system users is observed. Without the use of PTP, the total delay time for transport system users is 1731.5 seconds. When organizing a dedicated bus lane, the delay time is 1537.3 seconds (an improvement of $11.2 \%$ ). 
Active priority systems reduce user latency by $8.8 \%$ ("green extension") and 5.2\% ("stage recall").

\section{CONCLUSION}

Any PTP method is beneficial in terms of reducing the delay time for the transport system users. In the Russian Federation, the organization of dedicated bus lanes is most often used. The creation of a separate lane for public transport is expensive. However, more often, bus lane is created by reducing the number of lanes for personal transport. In some cases, if it is impossible to organize a dedicated lane for bus traffic (features of urban planning, insufficient road width), then using the active PTP can be an alternative way to reduce bus delays. At the same time, this method may have a less negative impact on the movement of personal transport than a dedicated lane. Due to the variety of characteristics of the road and PT route network in cities, it is not possible to develop a universal strategy with constant parameters. To reduce time delays in each specific locality, it is required to select the optimal event and parameters of the allocated lane and traffic light operating mode. At the same time, it is advisable to use the results of traffic simulation in projects.

\section{ACKNOWLEDGEMENT}

The research was funded by RFBR and Tyumen Region, number 20-48-720006 "Model for the transformation of urban transport systems with considering account the impact on society and the economy of the Covid-19 coronavirus pandemic".

\section{REFERENCES}

[1] Traffic intensity before, during and after intelligent lockdown measures in the Netherlands. https://www.ams-institute.org/news/traffic-intensity-during-and-afterintelligent-lockdown-measures-netherlands. Accessed on: 10 May 2021.

[2] Petrov, A.I. \& Petrova, D.A., Sustainability of transport system of large Russian city in the period of COVID-19: Methods and results of assessment. Sustainability (Switzerland), 12(18), p. 7644, 2020. DOI: 10.3390/su12187644.

[3] Coronavirus disease (COVID-19) travel advice, https://www.who.int/emergencies/ diseases/novel-coronavirus-2019/question-and-answers-hub/q-a-detail/coronavirusdisease-covid-19-small-public-gatherings. Accessed on: 10 May 2021.

[4] Tirachini, A. \& Cats, O., COVID-19 and public transportation: Current assessment, prospects, and research needs. Journal of Public Transportation, 22(1), pp. 1-34, 2020. DOI: $10.5038 / 2375-0901.22 .1 .1$.

[5] Sakamoto, K., Abhayantha, C. \& Kubota, H., Effectiveness of bus priority lane as countermeasure for congestion. Transportation Research Record, 2034, pp. 103-111, 2007. DOI: $10.3141 / 2034-12$.

[6] Eichler, M. \& Daganzo, C.F., Bus lanes with intermittent priority: Strategy formulae and an evaluation. Transportation Research Part B: Methodological, 40(9), pp. 731744, 2006. DOI: 10.1016/j.trb.2005.10.001.

[7] Hu, S.-X., Dong, J. Lianga, S.-D. \& Yuana P.-C., An approach to improve the operational stability of a bus line by adjusting bus speeds on the dedicated bus lanes. Transportation Research Part C: Emerging Technologies, 107, pp. 54-69, 2019. DOI: $10.1155 / 2020 / 3236841$.

[8] Alexey, F. \& Dmitrii, Z., Influence of the parameters of the bus lane and the bus stop on the delays of private and public transport. Sustainability (Switzerland), 12(22), pp. 1-18, 2020. DOI: 10.3390/su12229593. 
[9] Macedo, M.M. \& Bernardinis, M.A.P., Demand-side innovation policies and the planning of the public transportation system in the city of Curitiba (State of Paraná, Brazil). WIT Transactions on the Built Environment, vol. 182, WIT Press: Southampton and Boston, pp. 219-228, 24th International Conference on Urban Transport and the Environment, Aveiro, Portugal, 25-27 Jun. 2019.

[10] Lambas, M.E.L., Giuffrida, N., Ignaccolo, M. \& Inturri, G., Comparison between bus rapid transit and light-rail transit systems: A multi-criteria decision analysis approach. WIT Transactions on the Built Environment, vol. 176, WIT Press: Southampton and Boston, pp. 143-154. 23rd International Conference on Urban Transport and the Environment, Rome, Italy, 5-7 Sep. 2017.

[11] Cengiz, E.C., Bus rapid transit: An environmental friendly transport solution for Istanbul. International Journal of Transport Development and Integration, 1(1), pp. 54-62, 2017.

[12] Tatum, K., Parnell, K., Cekic, T.I. \& Knieling, J., Driving factors of sustainable transportation: Satisfaction with mode choices and mobility challenges in Oxfordshire and Hamburg. International Journal of Transport Development and Integration, 3(1), pp. 55-66, 2019.

[13] Grzelec, K. \& Jagiełło, A., The effects of the selective enlargement of fare-free public transport. Sustainability (Switzerland), 12(16), p. 6390, 2020.

DOI: 10.3390/SU12166390.

[14] Diakaki, C., Papageorgiou, M., Dinopoulou, V., Papamichail, I. \& Garyfalia, M., State-of-the-art and -practice review of public transport priority strategies. IET Intelligent Transport Systems, 9, pp. 391-406, 2015. DOI: 10.1049/iet-its.2014.0112.

[15] Bhouri N., Mayorano, F.J., Lotito, P.A., Salem, H.H. \& Lebacque, J.P., Public transport priority for multimodal urban traffic control. Cybernetics and Information Technologies, 15(5), 2015. DOI: 10.1515/cait-2015-0014.

[16] Shepelev, V., Aliukov, S., Nikolskaya, K. \& Shabiev, S., The capacity of the road network: Data collection and statistical analysis of traffic characteristics. Energies, 13(7), p. 1765, 2020. DOI: 10.3390/en13071765.

[17] PTV AG, PTV Vissim Manual. http://cgi.ptvgroup.com/vision-help/VISSIM_11_ ENG/. Accessed on: 11 Sep. 2020.

[18] Kalle, R.K., Kumar, P., Mohan, S. \& Sakata, M., Simulation-driven optimization of urban bus transport. WIT Transactions on the Built Environment, vol. 186, WIT Press: Southampton and Boston, pp. 97-108. 25th International Conference on Urban Transport and the Environment, Urban Transport, Aveiro, Portugal, 25 Jun. 2019. 